\title{
Aspectos facilitadores e desafios para a implementação de um modelo de educação permanente para a Vigilância Sanitária
}

\author{
Facilitating aspects and challenges for the implementation of a \\ permanent education model for Health Surveillance
}

\author{
Maria Júlia Pantojal,* \\ Claudia Passos Guimaraes \\ Rabelo" iD
}

Maria de Fátima Ferreira Francisco" iD
Universidade de Brasília (UNB), Brasília, DF, Brasil

" Agência Nacional de Vigilância Sanitária (Anvisa), Brasília, DF, Brasil

* E-mail: jpantoja@unb.br

Recebido: 13 maio 2020 Aprovado: 16 nov 2020

\section{RESUMO}

Introdução: O desenvolvimento de competências ocorre por meio da aprendizagem e envolve a aquisição de conhecimentos, habilidades e atitudes, e o desafio central que emerge para as organizações é disponibilizar oportunidades formais e informais de aprendizagem, integradas em programas de treinamento, desenvolvimento e educação. Objetivo: Identificar aspectos facilitadores e desafios para a implementação de um modelo de educação permanente para a Vigilância Sanitária. Método: Baseou-se em modelo de avaliação que contempla caracterização geral do contexto externo e interno, necessidades e dos componentes norteadores da estruturação dos processos formativos e análise técnica da avaliação de necessidades, do planejamento e execução e dos efeitos do programa de treinamento e desenvolvimento. Resultados: Os aspectos facilitadores identificados: competência legal de fomento aos estudos e pesquisas no âmbito do Sistema Nacional de Vigilância Sanitária (SNVS); normativos que ressaltam a valorização do desenvolvimento profissional; a realização de fóruns locais, regionais e federais, que especificam estratégias, desafios, eixos temáticos e áreas de formação para o SNVS; e a atuação da Agência Nacional de Vigilância Sanitária (Anvisa) como ente coordenador do Sistema, promovendo ações educativas em estados e municípios. Os desafios apontados: aprimoramento da articulação e integração dos entes do SNVS com outros setores da saúde; da atuação da Anvisa voltada para os demais entes do SNVS; da uniformidade na execução das ações; do comprometimento dos gestores com a análise de riscos e inovação dos processos de trabalho. Conclusões: Os processos para avaliação de necessidades e planejamento das estratégias de capacitação apresentam grandes oportunidades para aprimoramento, especialmente quando utiliza como referencial os diversos aspectos considerados relevantes pela literatura nas áreas de treinamento, desenvolvimento e educação.

PALAVRAS-CHAVE: Formação Profissional; Educação Permanente; Vigilância Sanitária 
specify strategies, challenges, thematic axes and training areas for the SNVS; and Anvisa's role as a coordinator of the System, promoting educational activities in states and municipalities. The challenges pointed out were: improvement of the articulation and integration of SNVS entities with other health sectors, of Anvisa's performance aimed at other SNVS entities; uniformity in the execution of actions; managers' commitment to risk analysis and innovation of work processes. Conclusions: The processes for assessing needs and planning training strategies present great opportunities for improvement, especially when the various aspects considered relevant by the literature in the areas of training, development and education are used as references.

KEYWORDS: Professional Training; Corporate Education; Health Surveillance

\section{INTRODUÇÃO}

Os avanços tecnológicos e a rápida obsolescência do conhecimento em um mundo globalizado e imerso em constantes e vertiginosas mudanças têm impulsionado o surgimento de novos modelos e múltiplas tecnologias educacionais. É dentro desse cenário, que a Educação Corporativa (EC) adquire relevância como modelo estratégico para a aquisição de competências complexas e de alta volatilidade necessárias aos novos arranjos organizacionais e às novas configurações dos trabalhos humanos, cujo desenvolvimento requer ações educacionais variadas, currículos e programas de aprendizagem contínua e de educação permanente ${ }^{1,2}$.

Alinhados a essa perspectiva, Mathias e Santos ${ }^{3}$ argumentaram que a EC retrata uma dinâmica que integra a promoção de ações de aprendizagem intrinsecamente vinculadas à estratégia da organização, por meio de uma diversidade de modalidades de ensino-aprendizagem, que ampliam as possibilidades de acesso ao conhecimento a todos os elos da cadeia de valor da organização: agentes de governança, servidores, parceiros, fornecedores e sociedade.

Em consonância com a literatura científica nacional e internacional na área da aprendizagem humana no trabalho, à medida que o desenvolvimento de competências ocorre por meio da aprendizagem envolvendo a aquisição de conhecimentos, habilidades e atitudes $(\mathrm{CHA})^{4,5,6,7,8}$, o desafio central que emerge para as organizações é disponibilizar oportunidades formais e informais de aprendizagem, integradas em programas de treinamento, desenvolvimento e educação (TD\&E) ${ }^{9,10}$.

Os referidos autores salientam que os processos de TD\&E podem gerar contribuições para a melhoria do desempenho de indivíduos e equipes de trabalho com vistas ao alcance dos objetivos estratégicos e ao pleno cumprimento da missão organizacional. Além da melhoria de desempenho profissional, tais processos podem favorecer a ampliação da autonomia e da responsabilidade para a prática individual e coletiva das atividades que gerem resultados para a instituição ${ }^{11,12,13,14}$.

Mais especificamente, no contexto organizacional do setor público, conforme menciona Bergue ${ }^{15}$, torna-se imprescindível a busca de CHA que impactem no resultado do trabalho realizado pelos agentes, por meio de processos de aprendizagem que envolvem pessoas, ambientes, tecnologias e dinâmicas sociais e de trabalho com inúmeras peculiaridades. Contudo, a aquisição de novos CHA é parte do desafio, impondo-se, além disso, a identificação de condições facilitadoras à transferência ou à aplicação desse conteúdo na transformação dos processos de trabalho e seus resultados, segundo parâmetros balizados pelo interesse público.

Nessa perspectiva, de acordo com Borges-Andrade et al. ${ }^{16}$, um processo de diagnóstico situacional de programas de TD\&E deve englobar um exame sistemático de informações contemplando duas principais etapas, quais sejam:

Etapa 1: caracterização geral do contexto externo e interno, bem como das necessidades e dos componentes norteadores da estruturação dos processos formativos;

Etapa 2: análise técnica detalhada dos elementos especificados em cada um dos três componentes do sistema TD\&E - avaliação de necessidades, planejamento e execução e avaliação de efeitos do programa de TD\&E.

Além dessas etapas, poderá envolver, ainda, uma análise das características do público-alvo e das variáveis de contexto facilitadoras à transferência e à mobilização das novas aprendizagens no trabalho.

Por meio do diagnóstico, é possível estabelecer um marco de referência para iniciar o planejamento de ações necessárias à implementação de melhorias e integração dos processos de formação e desenvolvimento profissional no âmbito do Sistema Nacional de Vigilância Sanitária (SNVS). Nesse sentido, são elencados alguns indicadores adotados com o objetivo de subsidiar uma análise abrangente de programas de TD\&E, conforme sistematizado no Quadro 1.

Com base nos indicadores elencados no Quadro 1, podem ser mapeadas condições favoráveis e pontos de vulnerabilidade à efetividade dos Processos de Formação Profissional do SNVS, os quais devem ser analisados detalhadamente, para que possam fundamentar um planejamento estratégico situacional ao desenvolvimento de ações focais e efetivas em relação aos problemas identificados.

Assim, por meio do diagnóstico situacional, o objetivo do presente artigo foi identificar aspectos facilitadores e desafios para a implementação de um modelo de educação permanente para a vigilância sanitária. Serão ainda discutidos os aspectos e as práticas utilizadas para a promoção da EC no Sistema. 
Quadro 1. Indicadores adotados na análise de programas de treinamento, desenvolvimento e educação.

\begin{tabular}{|c|c|c|}
\hline Dimensões & Categorias & Definições \\
\hline \multirow{6}{*}{$\begin{array}{l}\text { Contexto geral } \\
\text { dos processos } \\
\text { de formação }\end{array}$} & $\begin{array}{l}\text { Problemas/necessidades } \\
\text { norteadoras dos processos de } \\
\text { formação profissional do SNVS }\end{array}$ & $\begin{array}{l}\text { Vinculação de ações de aprendizagem aos objetivos e resultados estratégicos; inserção no } \\
\text { plano estratégico apoiado pela alta administração e disseminação de ações e resultados pela } \\
\text { instituição. }\end{array}$ \\
\hline & $\begin{array}{l}\text { Contexto de criação dos } \\
\text { processos de formação } \\
\text { profissional do SNVS }\end{array}$ & $\begin{array}{l}\text { Contexto de atuação dos processos de formação do SNVS: criação do SNVS, competências, } \\
\text { características organizacionais, perfil da força de trabalho, localização e dispersão geográfica, } \\
\text { entre outros. }\end{array}$ \\
\hline & $\begin{array}{l}\text { Diagnóstico e planejamento de } \\
\text { ações de aprendizagem }\end{array}$ & $\begin{array}{l}\text { Identificação das lacunas de competências atuais e de competências emergentes } \\
\text { nos públicos-alvo para fins de planejamento e execução das ações de capacitação } \\
\text { e desenvolvimento; condicionada à vinculação dos processos de aprendizagem ao } \\
\text { desenvolvimento de conhecimentos, habilidades e atitudes para solucionar problemas de } \\
\text { desempenho ou preparar a organização e a sociedade para o futuro. }\end{array}$ \\
\hline & $\begin{array}{l}\text { Desenvolvimento de ações de } \\
\text { aprendizagem }\end{array}$ & $\begin{array}{l}\text { Construção das soluções educacionais de forma compartilhada, a partir dos insumos gerados } \\
\text { pelo diagnóstico e do estabelecimento de parcerias com as equipes internas e externas à } \\
\text { organização detentoras dos CHA objetos de aprendizagem. }\end{array}$ \\
\hline & $\begin{array}{l}\text { Avaliação de ações de } \\
\text { aprendizagem nas diferentes } \\
\text { modalidades }\end{array}$ & $\begin{array}{l}\text { Sistemática de aferição da efetividade das ações educativas em nível da organização e do } \\
\text { indivíduo, com o objetivo de retroalimentar as etapas de planejamento e desenvolvimento } \\
\text { de ações de aprendizagem e gerar informações para disseminação e reconhecimento dos } \\
\text { investimentos direcionados aos processos de aprendizado continuado. }\end{array}$ \\
\hline & $\begin{array}{l}\text { Utilização de EaD em ações de } \\
\text { aprendizagem }\end{array}$ & $\begin{array}{l}\text { Incorporação de uma diversidade de TCl como estratégia para promoção do processo } \\
\text { educacional, a distância, adequada à cultura organizacional, características dos públicos-alvo } \\
\text { e aos objetivos dos eventos ofertados pela organização, com o objetivo de impulsionar os } \\
\text { resultados organizacionais. }\end{array}$ \\
\hline
\end{tabular}

Fonte: Morais ${ }^{17}$, com adaptações.

SNVS: Sistema Nacional de Vigilância Sanitária; CHA: conhecimentos, habilidades e atitudes; TCl: tecnologias da comunicação e informação; EaD: ensino a distância.

\section{MÉTODO}

A identificação dos aspectos facilitadores e desafios para a implementação de um modelo de educação permanente para a vigilância sanitária foi realizada contemplando duas etapas, com base no modelo de avaliação proposto por Borges-Andrade et al. ${ }^{16}$ :

i) Caracterização geral do contexto externo e interno, das necessidades e dos componentes norteadores da estruturação dos processos formativos;

ii) Análise técnica detalhada da avaliação de necessidades, do planejamento e execução e dos efeitos do programa de TD\&E.

Para a coleta das informações relativas a cada etapa do componente do diagnóstico situacional foram aplicadas técnicas de análise documental.

\section{Análise documental}

A primeira etapa do diagnóstico foi realizada a partir de análise documental ${ }^{18}$, considerando as publicações, os relatórios técnicos, os normativos, a legislação e os artigos fornecidos pela Agência Nacional de Vigilância Sanitária (Anvisa) e os materiais adicionais encontrados em bases virtuais de dados, apresentados no Quadro 2.

A análise dos documentos englobou a busca por núcleos de sentido e discursos comuns que possibilitassem a caracterização do SNVS e das práticas utilizadas para a promoção da EC no Sistema ${ }^{33,34}$.
A partir da bibliografia pesquisada foi verificado que há vários estudos teóricos e empíricos sobre a EC, porém, com carência de materiais que auxiliassem diretamente no processo de avaliação. Assim, optou-se por analisar na literatura fatores considerados relevantes para a estruturação e funcionamento de um sistema educacional norteado por um paradigma mais contemporâneo de EC que contribua efetivamente com o processo de geração de valor para a organização e para a cadeia de valor em que ela está inserida.

Os fatores e conceitos apresentados servirão como base para a elaboração de um roteiro que auxiliará tanto no processo de caracterização, quanto na avaliação dos programas de capacitação. A primeira parte do modelo proposto compreende um conjunto de itens a serem utilizados para caracterização do SNVS e das organizações que o compõem, conforme indicado no Quadro 3.

\section{RESULTADOS E DISCUSSÃO}

A seguir, serão apresentados os resultados obtidos a partir da análise documental sob forma dialogada, referenciando os aspectos considerados importantes pela literatura especializada.

\section{Caracterização geral do SNVS}

A caracterização do SNVS evidenciou sua complexidade e seus aspectos gerais e permitiu compreender seu funcionamento e identificar sua abrangência de atuação, quer seja em termos de competências e atribuições, quer seja no que tange aos aspectos estruturais, como o da dispersão geográfica. 
Quadro 2. Relação de documentos analisados.

\begin{tabular}{|l|c|}
\hline Documento & Ano \\
\hline Relatório final da I Conferência Nacional de Vigilância Sanitária ${ }^{19}$ & 2001 \\
\hline Plano Diretor de Vigilância Sanitária ${ }^{20}$ & 2007 \\
\hline Técnico em vigilância em saúde: diretrizes e orientações para formação ${ }^{21}$ & 2011 \\
\hline Gestão da educação em vigilância sanitária - Proposições regionais ${ }^{22}$ & $2012 / 2013$ \\
\hline Perfil da Vigilância Sanitária municipal no Brasile & 2014 \\
\hline Relatório do Fórum Nacional do Ciclo de Debates em Vigilância Sanitária: desafios e tendências ${ }^{24}$ & 2015 \\
\hline Caderno do Curso de Especialização em Gestão da Vigilância Sanitária ${ }^{25}$ & 2017 \\
\hline Política Nacional de Educação Permanente em Saúde ${ }^{26,27,28}$ & $2017,2007,2006,2004$ \\
\hline Compilado de procedimentos do Sistema Nacional de Vigilância Sanitária ${ }^{29}$ & 2019 \\
\hline $\begin{array}{l}\text { Programação integrada para formação e aperfeiçoamento profissional do Sistema Nacional de Vigilância } \\
\text { Sanitária - Capacita-Visa }{ }^{30}\end{array}$ & $2019,2018,2017,2016$ \\
\hline $\begin{array}{l}\text { Política Nacional de Atenção Básica }{ }^{31} \\
\text { Guia de Integração Atenção Básica e Vigilância Sanitária }{ }^{32}\end{array}$ & 2017,2018 \\
\hline
\end{tabular}

Fonte: Elaborado pelas autoras, 2020.

Quadro 3. Fatores e itens utilizados na caracterização do Sistema Nacional de Vigilância Sanitária.

\begin{tabular}{|l|l|}
\hline Fator & \multicolumn{1}{c|}{ Item } \\
\hline Organização & $\begin{array}{l}\text { Organização dos componentes } \\
\text { Área de atuação } \\
\text { Localização e dispersão geográfica } \\
\text { Força de trabalho (total e por tipo) } \\
\text { Missão/visão/valores } \\
\text { Plano estratégico vigente }\end{array}$ \\
\hline SEC & $\begin{array}{l}\text { Posição do SEC na estrutura } \\
\text { Perfil da força de trabalho }\end{array}$ \\
& Escolas, programas e ações ofertadas \\
& Estratégias de comunicação e divulgação \\
& Origem de investimentos \\
& Processos de EC - Avaliação de necessidades \\
& Processos de EC - Planejamento \\
& Processos de EC - Estratégias de execução \\
& Processos de EC - Avaliação \\
& Relação com processos organizacionais \\
& Relação com processos de RH \\
& Públicos atendidos \\
\hline
\end{tabular}

Fonte: Borges-Andrade et al. ${ }^{9}$.

SEC: Sistema de Educação Corporativa; EC: Educação Corporativa; RH: recursos humanos.

\section{Organização dos componentes}

Conforme disposto na Lei ${ }^{\circ} 9.782$, de 26 de janeiro de $1999^{36}$ :

Art. $1^{\circ} \mathrm{O}$ Sistema Nacional de Vigilância Sanitária compreende o conjunto de ações definido pelo $\S 1^{\circ}$ do art. $6^{\circ}$ e pelos arts. 15 a 18 da Lei $n^{\circ} 8.080$, de 19 de setembro de 1990, executado por instituições da Administração Pública direta e indireta da União, dos Estados, do Distrito Federal e dos Municípios, que exerçam atividades de regulação, normatização, controle e fiscalização na área de vigilância sanitária.

Dessa forma, o SNVS é composto por organizações públicas nas três esferas de poder, a partir das instituições conforme relação abaixo:
- Federal: Ministério da Saúde, Conselho Nacional de Saúde, Anvisa, Fundação Oswaldo Cruz (Fiocruz), Instituto Nacional de Controle de Qualidade em Saúde (INCQS);

- Estadual: Secretarias Estaduais de Saúde, Conselhos Estaduais de Saúde e Vigilâncias Sanitárias Estaduais; Laboratórios Centrais de Saúde Pública (LACEN);

- Municipal: Secretarias Municipais de Saúde, Conselhos Municipais de Saúde e Vigilâncias Sanitárias Municipais.

Identificou-se nas pesquisas a atuação do INCQS, que é uma Unidade Técnica da Fiocruz, com atuação nas áreas de ensino, de pesquisa e de tecnologias de laboratório, relativas ao controle da qualidade de insumos, produtos, ambientes e serviços sujeitos à ação da Vigilância Sanitária.

\section{Área de atuação}

No que tange a área de atuação, dada a complexidade e a singularidade do SNVS, optou-se por descrevê-la como transversal para delinear mais claramente a atuação do SNVS e não a das organizações que o compõem.

De acordo com as Leis $\mathrm{n}^{\circ} 8.080$, de 19 de setembro de $1990^{35}$, e $n^{\circ} 9.782 / 1999^{36}$, o SNVS compreende um conjunto de ações capaz de eliminar, diminuir ou prevenir riscos à saúde e de intervir nos problemas sanitários decorrentes do meio ambiente, da produção e circulação de:

- Bens de saúde: medicamentos, alimentos, saneantes, sangue, hemoderivados, cosméticos, produtos para a saúde, agrotóxicos e produtos fumígenos derivados do tabaco;

- Serviços de saúde: hospitais e clínicas, ambulatórios, serviços odontológicos, e especializados (hemodiálise, transplantes, oncologia) e serviços diagnósticos (clínicas radiológicas, laboratórios de análises clínicas); 
- Serviços de interesse da saúde: creches, clubes, locais de tatuagem, cemitérios, manicures etc.

\section{Localização e dispersão geográfica}

Os profissionais do SNVS estão localizados em todo o território nacional. Nos estados, além das Secretarias, há também os LACEN e, na esfera municipal, os Laboratórios Municipais de Saúde Pública e as Secretarias Municipais de Saúde. Além disso, algumas entidades representativas dos entes estaduais e municipais mantêm estreita interdependência com o SNVS. São elas: os Conselhos de Saúde Nacional, Estadual e Municipal, o Conselho Nacional de Secretários de Saúde (CONASS), o Conselho Nacional de Secretarias Municipais de Saúde (CONASEMS) e os Conselhos de Secretarias Municipais de Saúde (COSEMS).

\section{Força de trabalho}

A caracterização da força de trabalho foi realizada por esfera de poder. Para tal levantamento, além dos materiais disponibilizados foram realizadas pesquisas junto a sítios da internet que apresentavam atribuições das instituições, bem como caracterizavam suas respectivas forças de trabalho. No caso da Anvisa, utilizou-se ainda informações obtidas no Painel Estatístico de Pessoal, disponibilizado e mantido pelo Ministério da Economia ${ }^{37}$ (Quadro 4).
No âmbito federal, há uma ampla dispersão geográfica dos profissionais, uma vez que a Anvisa, além da sede em Brasília, possui coordenações e postos da Vigilância Sanitária espalhados por todas as cinco regiões do país. A Figura 1 apresenta dados da distribuição da força de trabalho da Anvisa, por região geográfica do país, os quais foram extraídos, em março de 2020, do Painel Estatístico de Pessoal, do Ministério da Economia ${ }^{37}$.

Embora se perceba uma maior concentração na região Centro-0este, em especial no Distrito Federal, onde está cerca de 51,5\% (1.414) da força de trabalho, há uma grande dispersão geográfica nas demais regiões. Fato que impõe um esforço maior para a formulação e a implementação de processos de formação, já que as sistemáticas de avaliação de necessidades, planejamento, execução e avaliação de resultados devem contemplar estratégias que permitam a inserção de atores geograficamente dispersos e com acesso a um conjunto de diferentes recursos e condições de trabalho e formação, além das necessidades regionais e locais, que variam com o perfil de cada localidade de atuação.

No âmbito estadual, o SNVS é composto por basicamente dois tipos de organizações, com atribuições distintas, conforme descrito no Quadro 5.

No âmbito estadual, as unidades da federação são compostas por atores com funções e papéis distintos e pouco conhecidos

Quadro 4. Quantitativo da força de trabalho dos profissionais que atuam no Sistema Nacional de Vigilância Sanitária, na esfera Federal, em 2020.

\begin{tabular}{|l|c|c|}
\hline Âmbito & Instituição & Descrição da força de trabalho \\
\hline Federal & Anvisa & $\begin{array}{c}2.748 \text { profissionais, sendo } 97,0 \% \text { concursados, os quais } 78,0 \% \text { possuem pelo } \\
\text { menos nível superior completo }\end{array}$ \\
\hline & INCQS & Mais de 450 profissionais, entre servidores públicos, terceirizados e bolsistas \\
\hline
\end{tabular}

Fonte: Ministério da Economia ${ }^{37}$, Instituto Nacional de Controle de Qualidade em Saúde ${ }^{38}$.

Anvisa: Agência Nacional de Vigilância Sanitária; INCQS: Instituto Nacional de Controle de Qualidade em Saúde.

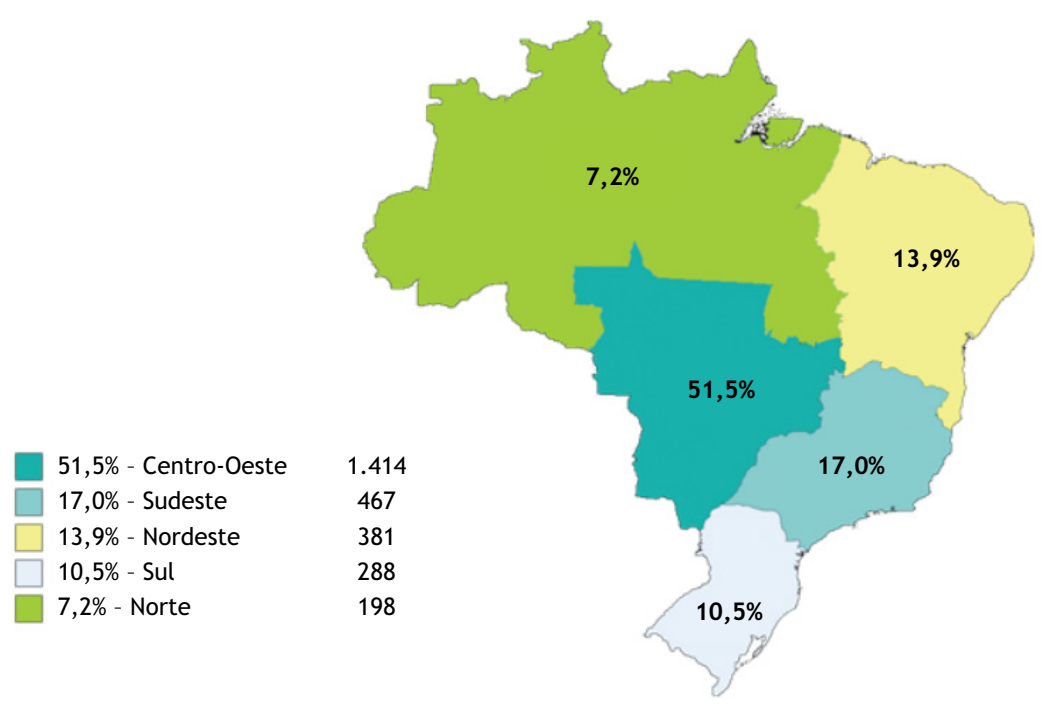

Fonte: Painel Estatístico de Pessoal, do Ministério da Economia ${ }^{37}$.

Figura 1. Distribuição da força de trabalho da Agência Nacional de Vigilância Sanitária (Anvisa), por região do Brasil, em 2020. 
Quadro 5. Características da força de trabalho dos profissionais que atuam no Sistema Nacional de Vigilância Sanitária, na esfera Estadual, em 2014.

\begin{tabular}{|l|c|l|}
\hline Âmbito & Instituição & \multicolumn{1}{c|}{ Descrição da força de trabalho } \\
\hline Estadual & $\begin{array}{c}\text { Órgãos de vigilância das } \\
\text { secretarias estaduais }\end{array}$ & $\begin{array}{l}\text { Cada secretaria e LACEN conta com suas respectivas equipes, apresentando, } \\
\text { em 2014, 3.684 profissionais atuando em atividades de vigilância } \\
\text { sanitária, sendo que 67,3\% possuíam ensino superior completo e 29,6\%, } \\
\text { ensino médio completo }\end{array}$ \\
\hline
\end{tabular}

Fonte: IBGE ${ }^{23}$.

LACEN: Laboratório Central de Saúde Pública.

Quadro 6. Características da força de trabalho dos profissionais que atuam no Sistema Nacional de Vigilância Sanitária, na esfera municipal, em 2014.

\begin{tabular}{|c|c|c|}
\hline \multirow{2}{*}{ Municipal } & Secretarias municipais & $\begin{array}{c}35.661 \text { profissionais, sendo que 63,4\% eram estatutários; 15,0\%, sem vínculo } \\
\text { permanente; 11,8\%, celetistas; 8,5\%, somente comissionados; e 1,1\%, estagiários }\end{array}$ \\
\cline { 2 - 3 } & Conselhos municipais & $\begin{array}{c}\text { Vinculados às Secretarias Municipais, às entidades representativas dos entes estaduais } \\
\text { e municipais, ou seja, os conselhos compostos por representantes do Governo, dos } \\
\text { prestadores de serviço, profissionais de saúde e usuários }\end{array}$ \\
\hline
\end{tabular}

Fonte: IBGE ${ }^{23}$.

no SNVS, com dinâmicas de ação e atuação próprias, que por vezes pode concorrer com os esforços realizados no âmbito geral do sistema. 0 perfil dos estados e dos municípios brasileiros mostra o quadro de pessoal dos serviços de Vigilância Sanitária estaduais com diversas formas de vínculos empregatícios, sendo que $81,1 \%$ são estatutários, $7,2 \%$, celetistas, $5,4 \%$, sem vínculo permanente, $4,0 \%$, somente comissionados e 2,3\%, estagiários ${ }^{23}$.

Por fim, com a visão no âmbito municipal é que se percebe a real extensão do desafio de se estruturar um sistema de educação que alcance todo o SNVS. Em 2014, dos 5.570 municípios do país, 5.448 possuíam estrutura específica de Vigilância Sanitária e 111 informaram possuir uma pessoa responsável pelas ações de vigilância sanitária, totalizando 5.559 municípios com profissionais responsáveis por ações de vigilância sanitária, independentemente da existência de estrutura específica. 0 quadro de pessoal era composto por 35.661 profissionais $^{23}$. 0 Quadro 6 apresenta, de forma resumida, uma visão aproximada do público a ser alcançado.

No âmbito municipal, além da questão geográfica, somam-se a disparidade entre os portes e a grande diferença nas necessidades de capacitação, além do grau de qualificação dos profissionais que atuam em cada localidade e do vínculo empregatício. Há ainda, nesse âmbito, a participação dos conselhos municipais, composto também por profissionais não vinculados à esfera pública e usuários do SNVS, o que requer um tratamento de adequação de linguagem e conteúdo, dada as assimetrias de formação e capacidade de engajamento.

Os dados coletados indicam um sistema com uma grande força de trabalho, distribuída no país, composta por um conjunto de diferentes perfis profissionais, além daqueles que não estão vinculados à nenhuma esfera de poder público, mas atuam como representantes. Tal diversidade de perfis forma um conjunto importante de questões a serem consideradas na estruturação de processos de formação em vigilância sanitária.

\section{Missão, visão e valores}

As Leis $\mathrm{n}^{\circ} 8.080 / 1990^{35}$ e $\mathrm{n}^{\circ}$ 9.782/199936 estabelecem a missão e os valores que o norteiam o SNVS, além de definir as atribuições, competências e princípios. A Lei $n^{\circ} 9.782 / 1999^{35}$ traz a descrição das competências no âmbito das três esferas de governo, delineando seus respectivos campos de atuação. Já a lei $\mathrm{n}^{\circ} 8.080 / 1990^{35}$ estabelece os princípios comuns tais como: universalidade de acesso aos serviços; participação da comunidade, entre outros.

Tais instrumentos asseguram um conjunto básico de pressupostos que possibilitam o alinhamento e uma visão do que é essencial para o desenvolvimento da força de trabalho envolvida no SNVS, fornecendo condições para identificar necessidades técnicas e comportamentais para o mapeamento de competências e estruturação dos programas de capacitação.

\section{Plano estratégico vigente}

Em 2007, foi elaborado o Plano Diretor de Vigilância Sanitária (PDVISA) que contempla as diretrizes norteadoras para a consolidação e o fortalecimento do SNVS, com ações propostas para o alcance da sua finalidade ${ }^{20}$. Esse documento pode ser visto como análogo a um planejamento estratégico de uma organização.

Tem como grande vantagem o fato de ter sido construído de forma participativa, envolvendo a coleta de percepções no âmbito de todas as esferas de atuação (municipal, estadual e federal). 0 plano contempla ainda desafios ligados à educação profissional, fornecendo subsídios para a formulação de estratégias mais adequadas para estruturação dos Processos de Formação do SNVS.

A Política Nacional de Educação Popular em Saúde (PNEPS) e as Diretrizes para Gestão da Educação em Vigilância Sanitária também são instrumentos norteadores que definem diretrizes para a formação e o desenvolvimento de trabalhadores e sua implementação ${ }^{22,26,27,28}$. 
A análise dos relatos do Ciclo de Debates realizado em 2015 e intitulado "Desafios e Tendências no campo da vigilância sanitária de produtos e serviços: qual a vigilância sanitária que a sociedade precisa?" permitiu identificar importantes estratégias de formação para o SNVS que podem apoiar as competências profissionais a serem desenvolvidas ${ }^{24}$.

\section{Considerações sobre os documentos analisados}

As informações identificadas na pesquisa documental permitiram verificar que existem elementos que favorecem a estruturação de um Sistema de EC mais dinâmico, moderno e profissionalizado que atenda a todo o SNVS. 0 Quadro 7 apresenta, de forma consolidada, aspectos relevantes identificados na caracterização.

A partir da caracterização foi possível analisar as possíveis articulações entre a oferta de cursos dos processos de formação, as competências legais do SNVS, os normativos na área de Saúde, como a PNEPS de 2004 e $2007^{26,28}$, a Portaria $\mathrm{n}^{\circ} 3.194$, de 28 de novembro de $2017^{27}$, e todos os demais documentos analisados, que serão expostos a seguir.

As Diretrizes de Gestão da Educação em Vigilância Sanitária trazem linhas norteadoras da ação educativa em vigilância sanitária com potencial de subsidiar a construção de planos, programas e projetos voltados para a formação profissional em vigilância sanitária. Estas diretrizes estão organizadas por eixos que especificam o modelo de organização das ações educacionais, a aproximação com as políticas de gestão do trabalho e os princípios bases dos processos educacionais, como o fomento ao desenvolvimento de competências concernentes às funções sociais da vigilância sanitária, priorização de metodologias ativas de ensino aprendizagem e a utilização de ferramentas ampliem o acesso dos profissionais nas iniciativas educacionais ofertadas ${ }^{22}$.

Mais especificamente, $\mathrm{O}$ Ciclo de Debates ${ }^{24}$ traduz importantes estratégias de formação para o SNVS, como: desenvolvimento de atividades educativas que alcancem o ensino fundamental e o ensino médio, com ampliação do Educanvisa e o Programa Saúde na Escola (PSE); integração com as áreas das secretarias de saúde responsáveis pelos programas de educação, a fim de difundir o conhecimento em vigilância sanitária e trocar saberes entre as diversas áreas; e elaboração de um programa permanente de educação sistematizado e de habilitação técnica para os profissionais de vigilância sanitária, com planos de capacitação para os servidores e responsabilização dos três entes do SNVS.

A PNEPS identifica pontos importantes para a formação profissional do trabalhador de vigilância sanitária, como a criação de uma instância colegiada para a gestão da educação em saúde. A Política traz como uma de suas principais funções a identificação das necessidades de formação e desenvolvimento em saúde, de forma cooperativa, articulando e incentivando a transformação das práticas em saúde.

No que diz respeito aos Fóruns Locais, Regionais e Federais, mais especificamente, o PDVISA realizado em 2006/2007 e ao Ciclo de Debates, em 2015, alguns elementos sinalizadores para a formação e desenvolvimento em vigilância sanitária podem ser destacados:

- Qualificação profissional com ênfase nas habilidades técnicas;

- Realização de eventos que favoreçam a integração dos profissionais de vigilância sanitária com os demais profissionais da área da Saúde e integrantes da sociedade civil;

- Identificação de necessidades de formação e definição de conteúdo de forma conjunta com os estados e municípios;

- Capacitação de gestores em vigilância sanitária, com ênfase na área de planejamento e financiamento;

- Utilização de tecnologias de educação a distância e treinamento em serviço;

Quadro 7. Aspectos facilitadores e vulnerabilidades identificados na caracterização do Sistema Nacional de Vigilância Sanitária,

\begin{tabular}{|c|c|}
\hline Aspectos facilitadores & Pontos de vulnerabilidade \\
\hline $\begin{array}{l}\text { - Competência legal de fomento aos estudos e pesquisas no âmbito } \\
\text { do SNVS } \\
\text { - } \quad \begin{array}{l}\text { Política Nacional de Educação Permanente em Saúde (2004) que } \\
\text { tem como funções importantes a valorização do desenvolvimento } \\
\text { profissional no SUS, de forma integrada e gestão colegiada }\end{array} \\
\text { - } \quad \begin{array}{l}\text { Realização de Fóruns locais, regionais e federais, que especificam } \\
\text { estratégias, desafios, eixos temáticos e áreas de formação para o } \\
\text { SNVS (2001, 2007, 2015) }\end{array} \\
\text { - } \quad \text { Diversidade de perfis profissionais que atuam no SNVS } \\
\text { - Normativos que explicitam que a aprendizagem continuada é } \\
\text { relevante para uma atuação de excelência no âmbito do SNVS } \\
\text { Atuação da Anvisa como ente coordenador do Sistema, promovendo } \\
\text { ações educativas em estados e municípios }\end{array}$ & $\begin{array}{l}\text { - Pouca articulação entre os entes do SNVS } \\
\text { - Dificuldade de integração e articulação com setores de saúde, } \\
\text { marcadamente as áreas da Vigilância em Saúde e Atenção Básica, } \\
\text { o que favorece uma postura competitiva e não colaborativa entre } \\
\text { tais atores } \\
\text { - } \quad \text { Atuação da Anvisa como órgão central e, de certa forma, distanciado } \\
\text { das necessidades reais dos demais entes do SNVS } \\
\text { - Fragmentação do SNVS, que se reflete em baixos níveis de integração } \\
\text { e uniformidade na execução das ações } \\
\text { - Papéis pouco definidos } \\
\text { Baixos níveis de comprometimento dos gestores com a análise de } \\
\text { riscos e inovação dos processos de trabalho } \\
\text { Distinções de porte, das condições e níveis de qualificação em cada } \\
\text { região e municípios }\end{array}$ \\
\hline
\end{tabular}

Fonte: Elaborado pelas autoras, 2020

SNVS: Sistema Nacional de Vigilância Sanitária; SUS: Sistema Único de Saúde; Anvisa: Agência Nacional de Vigilância Sanitária. 
- Qualificação dos profissionais de vigilância sanitária para a promoção de ações educativas para a sociedade;

- Capacitação voltada aos conselheiros de saúde.

É preciso considerar ainda outros importantes elementos como as demandas de temas estratégicos do governo, temas emergentes relativos às inovações tecnológicas e crescentes exigências na esfera internacional que podem exercer impactos no desenho e ofertas de aprendizagem no SNVS.

Diante do exposto, foi possível pontuar as categorias preliminares de componentes norteadores da formulação e do planejamento de um programa de aperfeiçoamento, apresentadas na Figura 2.

Nesta perspectiva, observa-se a integração de vários fatores influenciando na estruturação dos processos de formação, que atuam sobre oferta, demandas e temas estratégicos de governo, necessidades e gaps de competências dos estados e municípios, além das inovações tecnológicas.

\section{Formação no SNVS}

A Anvisa atua diretamente na gestão da educação, no âmbito do SNVS e possui entre as suas competências regimentais a coordenação da gestão da educação desse sistema, incluindo as ações para promoção da saúde em vigilância sanitária. Tais competências são realizadas por meio de dois importantes programas: Formação e Aperfeiçoamento Profissional em Vigilância Sanitária (Capacita-Visa) e Educação para Promoção da Saúde (Educanvisa).

Uma das ações do programa Capacita-Visa é publicar e apoiar a realização de eventos de capacitação para o SNVS (intrasetorial e interinstitucional), com o incentivo da adoção de estratégias de aprendizagem ativa. Ainda dentro do programa, a Anvisa estabelece parcerias com órgãos de educação e articula as instâncias educacionais nas secretarias estaduais e municipais de saúde ${ }^{28}$.

No eixo educação para promoção da saúde, o público-alvo é constituído de professores e alunos da educação infantil, ensino fundamental, médio e educação de jovens e adultos; profissionais de secretarias de educação e comunidade local. Entre as principais ações destacam-se o programa Educanvisa composto por módulos presencial e a distância e encontros de informação, educação e comunicação em saúde.

As atividades desenvolvidas pela Anvisa representam uma importante dimensão do sistema de educação em vigilância sanitária. Suas ações ampliam a perspectiva da aprendizagem contínua para além do ambiente organizacional da Agência, uma vez que coordena os processos formativos em vigilância sanitária de diversos entes do SNVS e da sociedade civil, articulando parcerias para otimização do desenvolvimento de competências.

Para analisar o grau de articulação entre os componentes norteadores da formulação e planejamento dos processos de formação no SNVS e da oferta dos Programas Capacita-visa e Educanvisa, os conteúdos foram sistematizados no Quadro 8 e sinalizam que os aspectos legais e normativos estão articulados e constituem possíveis indutores de um sistema de educação permanente em vigilância sanitária, além de fomentarem uma cultura de aprendizagem contínua.

É possível observar, ainda no Quadro 8, que as competências legais do SNVS especificam quatro grandes categorias de competências - regulação, normatização, controle e fiscalização - a serem desdobradas em $\mathrm{CHA}$ e desenvolvidas pelos profissionais, por meio dos processos de aprendizagem.

\section{Avaliação das ações de capacitação no âmbito do SNVS}

Feita a caracterização do SNVS e as considerações dos documentos analisados que fundamentam o desenvolvimento de estratégias voltadas para a qualificação dos profissionais de vigilância sanitária, é importante avaliar, de forma estruturada, o Capacita-Visa. Nesse sentido passaremos a uma avaliação mais direta do programa, fazendo uma comparação do programa com o que a literatura classifica como um Sistema de Educação Corporativa (SEC), considerando os aspectos apontados abaixo:

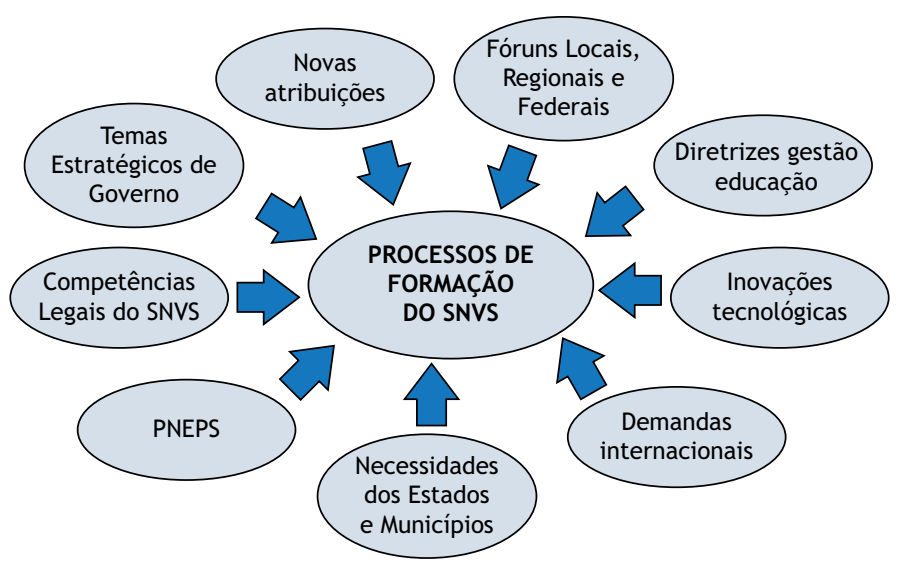

Fonte: Elaborada pelas autoras, 2020.

PNEPS: Política Nacional de Educação Popular em Saúde; SNVS: Sistema Nacional de Vigilância Sanitária

Figura 2. Categorias preliminares identificadas por meio da análise documental. 
Quadro 8. Pontos de articulação entre as competências legais do Sistema Nacional de Vigilância Sanitária (SNVS) e os documentos analisados.

\begin{tabular}{|c|c|c|c|c|}
\hline $\begin{array}{l}\text { Competências } \\
\text { do SNVS }\end{array}$ & $\begin{array}{l}\text { Funções da Política } \\
\text { Nacional de Educação } \\
\text { Permanente em Saúde }\end{array}$ & $\begin{array}{l}\text { Diretrizes do Plano } \\
\text { Diretor de Vigilância } \\
\text { Sanitária (PDVISA) }\end{array}$ & $\begin{array}{c}\text { Diretrizes para a Gestão da Educação em } \\
\text { Vigilância Sanitária }\end{array}$ & $\begin{array}{c}\text { Estratégias Relatório do } \\
\text { Fórum Nacional - Ciclo } \\
\text { de Debates: Desafios e } \\
\text { Tendências }\end{array}$ \\
\hline $\begin{array}{l}\text { Desenvolver } \\
\text { ações/ atividades } \\
\text { de regulação, } \\
\text { normatização, } \\
\text { controle e } \\
\text { fiscalização } \\
\text { em vigilância } \\
\text { sanitária, no } \\
\text { âmbito das } \\
\text { três esferas de } \\
\text { poder (federal, } \\
\text { estadual e } \\
\text { municipal) }\end{array}$ & $\begin{array}{l}\text { Identificar necessidades } \\
\text { de formação e } \\
\text { desenvolvimento em } \\
\text { saúde; } \\
\text { Construir estratégias e } \\
\text { processos que qualifiquem } \\
\text { a atenção e gestão em } \\
\text { saúde e fortaleçam o } \\
\text { controle social; } \\
\text { Mobilizar a formação de } \\
\text { gestores de sistemas, } \\
\text { ações e serviços em } \\
\text { saúde; } \\
\text { Propor políticas e } \\
\text { estabelecer negociações } \\
\text { interinstitucionais e } \\
\text { intersetoriais; } \\
\text { Articular e estimular } \\
\text { a transformação das } \\
\text { práticas de saúde e } \\
\text { educação da saúde } \\
\text { no SUS; } \\
\text { Estabelecer relações } \\
\text { cooperativas nas três } \\
\text { esferas de poder. }\end{array}$ & $\begin{array}{l}\text { Promover a qualificação } \\
\text { profissional em } \\
\text { vigilância sanitária; } \\
\text { Definir políticas } \\
\text { de formação para } \\
\text { integração da vigilância } \\
\text { sanitária com as } \\
\text { diversas áreas de saúde; } \\
\text { Fomentar a efetivação } \\
\text { de parcerias entre o } \\
\text { SNVS e instituição de } \\
\text { ensino superior e de } \\
\text { pesquisa; } \\
\text { Promover ações } \\
\text { educativas para difusão } \\
\text { da vigilância sanitária; } \\
\text { Desenvolver processos } \\
\text { de educação para a } \\
\text { sociedade quanto ao } \\
\text { consumo e uso de } \\
\text { serviços de saúde; } \\
\text { Desenvolver ações } \\
\text { educativas em } \\
\text { vigilância sanitária para } \\
\text { Conselheiros de Saúde. }\end{array}$ & $\begin{array}{l}\text { A programação das ações de vigilância } \\
\text { sanitária deve incorporar ações de educação } \\
\text { dos profissionais articuladas ao seu } \\
\text { trabalho, considerando os instrumentos de } \\
\text { planejamento do Sistema Único de Saúde } \\
\text { (Plano de Saúde, Programação e o Relatório } \\
\text { de Gestão), nas respectivas esferas de gestão; } \\
\text { As ações educacionais do SNVS devem } \\
\text { priorizar o risco sanitário, o planejamento } \\
\text { de base regional e a concepção de redes de } \\
\text { atenção à saúde; } \\
\text { A Gestão da Educação deve considerar as } \\
\text { políticas de Promoção e Atenção à Saúde em } \\
\text { suas interfaces com as ações de vigilância } \\
\text { sanitária; } \\
\text { A Gestão da Educação deve considerar } \\
\text { os sistemas de informação em saúde e } \\
\text { aqueles específicos em vigilância sanitária, } \\
\text { possibilitando a utilização de indicadores } \\
\text { epidemiológicos, assistenciais e outros } \\
\text { no planejamento das ações em vigilância } \\
\text { sanitária; } \\
\text { Os processos educacionais em vigilância } \\
\text { sanitária devem estar em consonância com } \\
\text { os princípios finalísticos e as diretrizes } \\
\text { organizacionais do SUS, fomentando } \\
\text { o desenvolvimento de competências } \\
\text { concernentes às funções sociais da } \\
\text { Vigilância Sanitária; } \\
\text { Os processos educacionais devem } \\
\text { priorizar metodologias ativas de ensino- } \\
\text { aprendizagem, com vistas à aprendizagem } \\
\text { significativa, valorização das respectivas } \\
\text { culturas e espaços de trabalho como locus } \\
\text { privilegiado para as ações educativas. }\end{array}$ & $\begin{array}{l}\text { E62. Educação continuada e } \\
\text { treinamento em serviço com } \\
\text { uso de EAD; } \\
\text { E63. Qualificar a gestão de } \\
\text { vigilância sanitária em todos } \\
\text { os níveis do Sistema, em } \\
\text { especial o Planejamento e } \\
\text { Financiamento; } \\
\text { E70. Política pública para } \\
\text { formação de Fiscais de } \\
\text { vigilância sanitária; } \\
\text { E87. Promover atividades de } \\
\text { educação junto à sociedade } \\
\text { civil; } \\
\text { E89. Utilizar a Ouvidoria } \\
\text { como estratégia de } \\
\text { educação; } \\
\text { E91. Integração com as áreas } \\
\text { de Educação permanente das } \\
\text { Secretarias de saúde; } \\
\text { E92. Definir em tripartite } \\
\text { conteúdo básico de } \\
\text { capacitação a ser oferecido } \\
\text { pelo município com base na } \\
\text { realidade local; } \\
\text { E93. Preparar os profissionais } \\
\text { de vigilância sanitária para } \\
\text { atuar em educação sanitária; } \\
\text { E94. Regulamentar } \\
\text { capacitação para o ingresso } \\
\text { de novos profissionais em } \\
\text { vigilância sanitária. }\end{array}$ \\
\hline
\end{tabular}

Fonte: Elaborada pelas autoras, 2020.

SUS: Sistema Único de Saúde; SNVS: Sistema Nacional de Vigilância Sanitária.

- Posição do SEC na estrutura;

- $\quad$ Perfil da força de trabalho;

- Escolas, programas e ações ofertadas;

- Estratégias de comunicação e divulgação;

- $\quad$ Processos de EC;

- Relação com processos organizacionais;

- Relação com processos de recursos humanos;

- $\quad$ Públicos atendido.

O SEC é mais estratégico quando tem condições de atuar de forma autônoma ou está situado em uma posição de proximidade ao centro decisório da instituição.

No caso do SNVS, que é um sistema composto por várias instituições com vários centros de poder, entende-se que a vinculação decisória mais adequada é a da autoridade máxima do órgão coordenador do sistema.

Quanto aos programas e às ações de capacitação, é importante lembrar que, de acordo com Eboli et al. ${ }^{39}$, a criação das escolas, programas e ações de capacitação podem ser considerados como o coração de um SEC, pois trata-se da estratégia utilizada para o agrupamento dos conteúdos a fim de atender as necessidades mapeadas. Sua existência deve estar, claramente, vinculada às necessidades estratégicas e, além de auxiliar no processo de vinculação das ações realizadas em relação às necessidades estratégicas e dos públicos mapeados, as escolas auxiliam na organização e no desenvolvimento dos conhecimentos, além de facilitarem o processo de comunicação e divulgação dos serviços.

Quando se tem uma rede complexa como a do SNVS, com necessidades variadas, como identificado, o desenho das escolas mostra-se como ferramenta essencial para que se consiga atender ao propósito de fortalecer as competências organizacionais necessárias, em especial aquelas que possuem caráter de transversalidade.

Conforme disponibilizado no portal corporativo da Anvisa ${ }^{30}$, anualmente é publicado, sob a forma de um caderno eletrônico, o conjunto de ações de capacitação ofertadas no âmbito do SNVS, nas três esferas de gestão. Nesse sentido, avaliar o quanto as ações ofertadas se aproximam da configuração do que a literatura chama de escolas pode auxiliar no processo de checagem do quanto os cursos ofertados pelo Capacita-Visa conseguem atender a diversidade de demandas e a complexidade dos desafios 
apresentados. Para formar uma visão um pouco mais abrangente, optou-se por considerar as publicações dos cursos ofertados no período de 2016 a 2019.

Os cursos ofertados são agrupados por área temática e apresentados individualmente, trazendo informações sobre: nome, instituição realizadora, carga horária, período de realização, local, objetivos e conteúdo do curso, modalidade e público-alvo. Considerando o período de 2016 a 2019, tem-se uma oferta total de 595 cursos em 18 áreas temáticas. A Tabela apresenta de forma consolidada o quantitativo de ações ofertadas por tema.

Analisando os dados de forma conjunta, é possível perceber uma concentração maior de ações ofertadas nas áreas temáticas de Fiscalização e inspeção, Serviços de saúde e transversais, que, juntas, correspondem a 63,0\% das ações ofertadas ao longo dos últimos anos. Essas áreas temáticas, além de apresentarem o maior quantitativo de ações, constituem ofertas regulares que, embora variem quantitativamente a cada ano, estão presentes regularmente, o que, dada a estratégia utilizada para o levantamento de oportunidades de capacitação, pode indicar que, na visão do sistema, tais temas são prioritários para o desenvolvimento dos profissionais que atuam no SNVS.

Adicionalmente, embora apresentem um quantitativo menor, as ações nas áreas de Agrotóxicos; Sangue, tecidos, células e órgãos; Saúde do trabalhador e Serviços de interesse para a saúde, podem ser consideradas também como eixos importantes, pois estão presentes de forma regular nos últimos quatro anos.
Considerando o conjunto das ofertas presentes na publicação eletrônica Capacita-Visa, é possível constatar que a sistemática de capacitação e ofertas se assemelha muito aos sistemas tradicionais de catálogos de cursos e, embora englobe temas que se perpetuem ao longo do período avaliado, não há qualquer indicação quanto à formação de escolas e nem de que tais temas, de forma geral, estejam intencionalmente alinhados às competências organizacionais ou necessidades estratégicas do Sistema. Entretanto, chama atenção os cursos agrupados sob o tema Transversais, que apresentam conteúdos mais claramente dirigidos às questões comuns, como formação profissional da vigilância sanitária, considerando ainda diferentes níveis de gradação de aprendizagem, que vão desde cursos introdutórios até cursos de especialização.

Esse agrupamento, embora denominado de forma mais generalista, representa um dos eixos que, aparentemente estão mais relacionados às competências organizacionais e possuem relação direta com a missão institucional e atribuições comuns aos integrantes do SNVS.

Assim, de forma geral, as ações ofertadas atendem a várias necessidades ligadas a aspectos técnicos e normativos do SNVS, todavia, dada a ausência de um processo claramente estruturado de avaliação das necessidades de aprendizagem, bem como de definição das competências organizacionais necessárias para a atuação do SNVS, o Programa Capacita-Visa atualmente é estruturado com base na consolidação das percepções e esforços individuais dos integrantes do SNVS. Não há, dessa forma, uma análise sistemática dos aspectos relacionados ao contexto de

Tabela. Oferta de cursos aos profissionais do Sistema Nacional de Vigilância Sanitária, por área temática, disponibilizados por meio da publicação eletrônica Capacita-Visa, nos anos de 2016 a 2019.

\begin{tabular}{|c|c|c|c|c|c|}
\hline Área temática & 2016 & 2017 & 2018 & 2019 & TOTAL \\
\hline Agrotóxicos & 6 & 5 & 2 & 1 & 14 \\
\hline Alimentos & - & 13 & 14 & 4 & 31 \\
\hline Cosméticos & - & - & - & 1 & 1 \\
\hline Fiscalização e inspeção & 45 & 16 & 72 & 34 & 167 \\
\hline Inclusão produtiva & 1 & - & 2 & 1 & 4 \\
\hline Laboratórios de saúde pública & - & 1 & 4 & - & 5 \\
\hline Monitoramento de produtos sujeitos à vigilância sanitária & - & - & 10 & 4 & 14 \\
\hline Monitoramento pós-uso & 6 & 4 & - & - & 10 \\
\hline Ouvidoria & 1 & - & - & - & 1 \\
\hline Saneantes & 1 & 1 & - & - & 2 \\
\hline Sangue, tecidos, células e órgãos & 14 & 6 & 6 & 2 & 28 \\
\hline Saúde do trabalhador & 11 & 5 & 18 & 9 & 43 \\
\hline Serviços de interesse para a saúde & 8 & 2 & 9 & 9 & 28 \\
\hline Serviços de saúde & 41 & 14 & 33 & 29 & 117 \\
\hline Sistemas de informação & - & 3 & 5 & 20 & 28 \\
\hline Tabaco & 3 & 4 & 2 & - & 9 \\
\hline Transversais & 30 & 10 & 41 & 9 & 90 \\
\hline Vigilância ambiental & 3 & - & - & - & 3 \\
\hline Total geral & 170 & 84 & 216 & 125 & 595 \\
\hline
\end{tabular}

Fonte: Elaborada pelas autoras, 2020. 
trabalho, lacunas de competências técnicas e comportamentais, características do público-alvo (sociodemográficas, psicossociais, motivacionais) e domínios de aprendizagem. Este tipo de análise pode influenciar tanto no engajamento e comprometimento dos indivíduos com o processo de aprendizagem, quanto na qualidade e adequação do planejamento das opções de aprendizagem às especificidades dos contextos e clientelas envolvidas.

Ainda, as atividades relativas à identificação de necessidades de TD\&E no âmbito do SNVS ocorrem de forma pouco estruturada, uma vez que os cursos são ofertados de acordo com as demandas recebidas dos entes do SNVS, que, por meio dos seus representantes, indicam opções de capacitação mais importantes e adequadas. Dessa forma, percebe-se que é tênue a caracterização das lacunas de competências em termos de CHA atuais e emergentes, com o objetivo de solucionar um problema advindo de um gap de competências e de preparar os profissionais do SNVS para o futuro.

Ressalta-se que o processo pouco estruturado de análise das lacunas de competências tende a apresentar ofertas difusa e pouco focadas no desenvolvimento de competências essenciais a todo SNVS e a pulverização de recursos aportados para as ações de TD\&E. Além disso, pode estar ausente o aprimoramento dos aspectos didáticos, das abordagens educativas para adultos no contexto de trabalho e do uso de tecnologias ativas de aprendizagem, pontos importantes para que a aprendizagem seja efetiva, em consonância com a PNEPS e as Diretrizes de Gestão da Educação em Vigilância Sanitária.

Quanto às estratégias de execução, utilizando como referência os cursos ofertados em 2019, percebe-se que, dos 125 cursos ofertados, apenas 27 , o equivalente a $21,6 \%$, são ofertados em modalidade virtual. Considerando a grande dispersão geográfica e o quantitativo de profissionais envolvidos no processo e a estratégia predominante de oferta de ações, que é presencial, percebe-se um descompasso entre a capacidade de atendimento do Programa, tanto em relação à necessidade quantitativa, quanto à acessibilidade para participação, dados os custos e limitações que cercam a realização de ações presenciais.

No material pesquisado não se encontrou referência a processos estruturados para avaliação dos resultados obtidos, como informações de cunho mais gerencial ou avaliações indicadas pela literatura. As informações gerenciais relacionam-se aos quantitativos e percentuais de profissionais do SNVS que foram capacitados, as horas de capacitação por profissional, o investimento per capita, entre outros. As avaliações indicadas pela literatura incluem a satisfação dos participantes em relação às ações ofertadas, o grau de aprendizagem e a retenção do conteúdo, a eficácia e a efetividade dos resultados alcançados com a participação nas ações.

Com relação à interação dos programas com os processos organizacionais, percebe-se uma relação clara, uma vez que as áreas temáticas utilizadas para o agrupamento podem ser facilmente associadas às diversas áreas de atuação do SNVS, em suas respectivas esferas de atuação. Esta relação vai ao encontro da premissa colocada pela PNEPS de as ações de formação refletirem o contexto e a necessidade específica de cada instituição.
Quanto à relação do Programa e das ações ofertadas com outros processos de gestão de pessoas, não se encontrou uma relação direta entre a participação dos profissionais nas ações de formação com quaisquer processos relacionados à gestão do desempenho, progressão e promoção funcional seja na carreira específica ou para cargos de gestão, ou mesmo políticas relacionadas à melhoria da qualidade de vida e retenção de profissionais.

Do exposto, podemos destacar alguns aspectos que podem facilitar a implementação de um modelo de educação permanente para a vigilância sanitária como a sistematização dos processos de avaliação de necessidades, de forma a considerar as competências organizacionais, conciliando assim interesses gerais do SNVS com as necessidades locais das entidades que o compõem e dos profissionais que atuam direta ou indiretamente no SNVS. Tal sistematização pode oferecer melhores bases para um processo ativo e sistêmico de planejamento das ações ofertadas, considerando prioridades estratégias em detrimento de esforços e necessidades individuais. Este pode ser considerado um desafio importante, considerando a complexidade do SNVS, a dispersão geográfica, as condições de trabalho e formação, as necessidades regionais e locais, que variam com o perfil de cada localidade de atuação.

Soma-se, ainda, a importância de um planejamento da oferta baseado na ampliação do uso de tecnologias instrucionais de educação a distância, em função especialmente da dispersão geográfica dos atores e profissionais envolvidos no processo. 0 uso desse tipo de tecnologia, além de ampliar a capacidade de alcance e oferta das ações educacionais, pode fornecer condições menos onerosas para capacitação dos envolvidos, evitando gastos tradicionais com locação de espaços e deslocamento de participantes.

Quanto ao público atendido, pela diversidade de cursos e públicos descritos nas ofertas, bem como pela ampliação e variação das áreas temáticas, percebe-se que há preocupação em se abranger uma diversidade de profissionais, porém, dada a ausência de dados e informações sobre a participação das pessoas nas ações, não se pode ter uma visão mais clara do real público atendido.

\section{CONCLUSÕES}

Após a realização da pesquisa documental, foi possível formar uma visão geral do SNVS e dos esforços de promoção da educação no Sistema.

Nesse sentido, é importante que o processo de proposição de um modelo de EC que consiga atender as diferentes necessidades dos atores e do sistema de forma geral considere fatores relevantes da literatura que contribuíam para a formação e o desenvolvimento dos profissionais do SNVS.

Os aspectos facilitadores identificados: competência legal de fomento aos estudos e pesquisas no âmbito do SNVS; a Política Nacional de Educação Permanente em Saúde (2004), que tem como funções importantes a valorização do desenvolvimento profissional no SUS, de forma integrada e gestão colegiada; a realização de Fóruns locais, regionais e federais, que especificam estratégias, desafios, eixos temáticos e áreas de formação 
para o SNVS (2001, 2007, 2015); a diversidade de perfis profissionais que atuam no SNVS; os normativos que explicitam que a aprendizagem continuada é relevante para uma atuação de excelência no âmbito do SNVS; e, por fim, a atuação da Anvisa como ente coordenador do Sistema, promovendo ações educativas em estados e municípios.

Os desafios apontados: aprimoramento da articulação entre os entes do SNVS e da integração e articulação com setores de saúde, marcadamente as áreas da Vigilância em Saúde e Atenção Básica, o que favorece uma postura competitiva e não colaborativa entre tais atores; atuação da Anvisa, como órgão central, baseada nas necessidades reais dos demais entes do SNVS; ações para melhorar os níveis de integração e uniformidade na execução das ações; superar o baixo comprometimento dos gestores com a análise de riscos e inovação dos processos de trabalho; definição clara das distinções de porte, das condições e níveis de qualificação em cada região e municípios.

Ressalta-se também a importância de que sejam realizados esforços direcionados ao mapeamento das competências organizacionais e individuais do Sistema, considerando as diferentes esferas de atuação e atores envolvidos. Tal mapeamento será essencial para que o desenho dos programas e as ações de formação possam estar devidamente articulados e contribuam efetivamente para o desenvolvimento estratégico do SNVS.

Por fim, entende-se que, a partir desse conjunto de questões pontuadas, seja possível construir uma proposta de sistema educacional que, ao considerar de forma abrangente os aspectos relevantes pela literatura, atenda as demandas e necessidades dos diversos atores que compõem o SNVS e que agreguem valor aos profissionais de forma específica e ao sistema de forma geral.

\section{REFERÊNCIAS}

1. Meister JC. Educação corporativa: a gestão do capital intelectual através das universidades corporativas. São Paulo: Makron; 1999.

2. Abbad G, Mourão L. Avaliação de necessidades de TD\&E: proposição de um novo modelo. Rev Adm Mackenzie. 2012;13(6):107-37.

3. Mathias EF, Santos GL. As comunidades virtuais como instrumento de educação corporativa: estudo de caso no tribunal de contas da união. Rev Serv Publ. 2014;65(3):32134. https://doi.org.br/10.21874/rsp.v65i3.627

4. Brandão HP, Borges-Andrade JE, Guimarães TA. Desempenho organizacional e suas relações com competências gerenciais, suporte organizacional e treinamento. Rev Adm. 2012;47(4):523-39. https://doi.org/10.5700/rausp1056

5. Tasca JE, Ensslin L, Ensslin SR. A construção de um referencial teórico sobre a avaliação de desempenho de programas de capacitação. Ensaio Aval Pol Publ Educ. 2013;21(79):203-38. https://doi.org/10.1590/S0104-40362013000200003

6. Sonnentag $\mathrm{S}$, Niessen C, Ohly S. Learning at work: training and development. In: Chmiel N, editor. An introduction to work and organizational psychology: an european perspective. Hoboken: John Wiley \& Sons; 2008. p. 249-89.

7. Abbad G, Borges-Andrade JE. Aprendizagem humana em organizações e trabalho. In: Zanelli JC, Borges-Andrade $\mathrm{JE}$, Bastos AVB, organizadores. Psicologia, organizações e trabalho no Brasil. Porto Alegre: Artmed; 2004. p. 244-84.

8. Pantoja MJ, Borges-Andrade JE. Contribuições teóricas e metodológicas da abordagem multinível para o estudo da aprendizagem e transferência nas organizações. In: Anais do $26^{\circ}$ Encontro da Associação Nacional de Programas de Pós-Graduação em Administração; Salvador, Brasil. Maringá: Associação Nacional de Programas de Pós-Graduação em Administração; 2002.

9. Borges-Andrade JE, Abbad G, Mourão L. Treinamento, desenvolvimento e educação em organizações e trabalho: fundamentos para a gestão de pessoas. Porto Alegre: Artmed; 2006.
10. Antonello CS, Pantoja MJ. Aprendizagem e o desenvolvimento de competências. In: Pantoja MJ, Camões MRS, Bergue ST. Gestão de pessoas: bases teóricas e experiências no setor público. Brasília: Escola Nacional de Administração Pública; 2010. p. 49-142.

11. Goldstein IL. Training in work organizations. In: Dunnette MD, Triandis HC, Hough LM. Handbook of industrial and organizational psychology. Palo Alto: Consulting Psychologists; 1990. p. 507-619

12. Zarifian P. Objetivo competência: por uma nova lógica. São Paulo: Atlas; 2001.

13. Fleury MTL, Fleury A. Construindo o conceito de competência. Rev Adm Contemp. 2001;5(esp):183-96. https://doi.org/10.1590/S1415-65552001000500010

14. Freitas IA, Brandão HP. Trilhas de aprendizagem como estratégia para desenvolvimento de competências. Maringá: Associação Nacional de Pós Graduação e Pesquisa em Administração; 2005[acesso 2 abr 2020]. Disponível em: http://www.anpad.org.br/admin/pdf/enanpad2005gpra-0316.pdf

15. Bergue ST. Gestão estratégica de pessoas no setor público. São Paulo: Atlas; 2014.

16. Borges-Andrade JE, Abbad GS, Mourão L. Modelos de avaliação e aplicação em TD\&E. In: Abbad GS, Mourão L, Meneses PPM, Zerbini T, Borges-Andrade JE, Villas Boas R, organizadores. Medidas de avaliação em treinamento, desenvolvimento e educação. Porto Alegre: Artmed; 2012. p. 20-35.

17. Morais QC. Educação a distância integrada à educação corporativa: estudo de caso [dissertação]. Brasília: Universidade de Brasília; 2017.

18. Creswell JW. Projeto de pesquisa: métodos qualitativo, quantitativo e misto. 2a ed. Porto Alegre: Artmed; 2007.

19. Agência Nacional de Vigilância Sanitária - Anvisa. Relatório final da $1^{\text {a }}$ conferência nacional de vigilância sanitária. Brasília: Agência Nacional de Vigilância Sanitária; 2001. 
20. Agência Nacional de Vigilância Sanitária - Anvisa. Plano diretor de vigilância sanitária. Brasília: Agência Nacional de Vigilância Sanitária; 2007[acesso 30 mar 2020]. Disponível em: http:// portal.Anvisa.gov.br/documents/33856/396770/Plano+Diretor +de+Vigil\%C3\%A2ncia+Sanit\%C3\%A1ria+-+PDVISA+\%28arquivo+c ompleto\%29/68870fac-3f94-474e-89dc-96eea4fb5850

21. Ministério da Saúde (BR). Técnico em vigilância em saúde: diretrizes e orientações para a formação. Brasília: Ministério da Saúde; 2011.

22. Agência Nacional de Vigilância Sanitária - Anvisa. Diretrizes para a gestão da educação em vigilância sanitária na política de educação permanente do Sistema Único de Saúde (SUS). Brasília: Agência Nacional de Vigilância Sanitária; 2011[acesso 30 mar 2020]. Disponível em: http://portal.anvisa.gov.br/ documents/33856/396770/Diretrizes+para+a+gestao+da+educ acao+em+vigilancia/95019354-13a9-4a05-861b-7a8409dcb517

23. Instituto Brasileiro de Geografia e Estatística - IBGE. Perfil dos estados e dos municípios brasileiros: vigilância sanitária 2014. Rio de Janeiro: Instituto Brasileiro de Geografia e Estatística; 2014.

24. Agência Nacional de Vigilância Sanitária - Anvisa. Relatório do fórum nacional: ciclo de debates: desafios e tendências. Brasília: Agência Nacional de Vigilância Sanitária; 2015.

25. Ramos L, Padilha RQ, Lima VV, Pereira SMSF, Costa EA. Curso de especialização em gestão da vigilância sanitária. São Paulo: Instituto Sírio-Libanês de Ensino e Pesquisa; 2017.

26. Ministério da Saúde (BR). Portaria $N^{\circ} 1.996$, de 20 de agosto de 2007. Dispõe sobre as diretrizes para a implementação da política nacional de educação permanente em saúde. Diário Oficial União. 20 ago 2007.

27. Ministério da Saúde (BR). Portaria $N^{\circ} 3.194$, de 28 de novembro de 2017. Dispõe sobre o programa para o fortalecimento das práticas de educação permanente em saúde no Sistema Único de Saúde Proeps-SUS. Diário Oficial União. 30 nov. 2017.

28. Ministério da Saúde (BR). Portaria No 198, de 13 de janeiro de 2004. Institui a política nacional de educação permanente em saúde como estratégia do Sistema Único de Saúde para a formação e o desenvolvimento de trabalhadores para o setor e dá outras providências. Diário Oficial União. 15 fev 2004

29. Agência Nacional de Vigilância Sanitária - Anvisa. Compilado de procedimentos do sistema nacional de vigilância sanitária. Brasília: Agência Nacional de Vigilância Sanitária; 2019.

30. Agência Nacional de Vigilância Sanitária - Anvisa. Capacitavisa. Brasília: Agência Nacional de Vigilância Sanitária; 2020[acesso 2 abr 2020]. Disponível em: https://www.gov. $\mathrm{br} / a n v i s a / p t-b r / a s s u n t o s / e d u c a c a o e p e s q u i s a / c a p a c i t a-v i s a$

31. Ministério da Saúde (BR). Portaria $N^{\circ} 2.436$, de 21 de setembro de 2017. Aprova a política nacional de atenção básica, estabelecendo a revisão de diretrizes para a organização da atenção básica, no âmbito do Sistema Único de Saúde (SUS). Diário Oficial União 29 set 2017.

32. Ministério da Saúde (BR). Guia política nacional de atenção básica: módulo 1: integração atenção básica e vigilância em saúde. Brasília: Ministério da Saúde; 2018.

33. Flick U. Introdução à pesquisa qualitativa. $3 a$ ed. Porto Alegre: Artmed; 2009.

34. Sá-Silva JR, Almeida CD, Guindani JF. Pesquisa documental: pistas teóricas e metodológicas. Rev Bras Hist Cienc Soc. 2009;1(1):1-15.

35. Brasil. Lei № 8.080 , de 19 de setembro de 1990. Dispõe sobre as condições para a promoção, proteção e recuperação da saúde, a organização e o funcionamento dos serviços correspondentes e dá outras providências. Diário Oficial União. 20 set 1990.

36. Brasil. Lei № 9.782, de 26 de janeiro de 1999. Define o Sistema Nacional de Vigilância Sanitária, cria a Agência Nacional de Vigilância Sanitária, e dá outras providências. Diário Oficial União. 27 jan 1999.

37. Ministério da Economia (BR). Painel estatístico de pessoal. Brasília: Ministério da Economia; 2020[acesso 2 abr 2020]. Disponível em: http://painel.pep.planejamento. gov.br/QvAJAXZfc/opendoc.htm?document=painelpep. qvw\&lang=en-US\&host=Local\&anonymous=true

38. Instituto Nacional de Controle de Qualidade em Saúde - INCQS. Estrutura. Rio de Janeiro: Fundação Oswaldo Cruz; 2020[acesso 2 abr 2020]. Disponível em: https://www.incqs.fiocruz.br/ index.php?option=com_content\&view=article\&tid=74\&ltemid=70

39. Eboli M, Hourneauxjr F, Cassimiro W. Educação corporativa e os desafios para sua efetivação: processo de implementação e fatores críticos de sucesso. In: Menezes JM, Lopes JJ, coordenadores. Diálogos de gestão: novos ângulos e várias perspectivas. Curitiba: JML; 2013. p. 3-53.

\section{Agradecimentos}

As autoras agradecem a equipe da Anvisa que apoiou integralmente esse trabalho, em especial, Fernanda Horne da Cruz, Janaína Lopes Domingos, Lilian Fernandes da Cunha, Mariangela Torchia do Nascimento e Rosaura Maria da Costa Hexsel.

\section{Contribuição dos Autores}

Pantoja MJ - Concepção, planejamento (desenho do estudo), aquisição, análise, interpretação dos dados e redação do trabalho. Rabelo CPG, Francisco MFF - Redação do trabalho. Todos os autores aprovaram a versão final do trabalho.

Os autores informam não haver qualquer potencial conflito de interesse com pares e instituições, políticos ou financeiros deste estudo. 